\title{
Team Cognition Approach in Agile Software Development
}

\author{
Raj Kumar Goel ${ }^{1}$, Chandra Shekhar Yadav ${ }^{1}$, Shweta Vishnoi ${ }^{2, *}$, Laxman Singh ${ }^{3}$ and Praveen \\ Pachauri $^{4}$
}

\author{
${ }^{I}$ Department of Computer Science \& Engineering, Noida Institute of Engineering \& Technology, Greater Noida, India \\ ${ }^{2}$ Department of Physics, Noida Institute of Engineering \& Technology, Greater Noida, India \\ ${ }^{3}$ Department of Electronics and Communication, Noida Institute of Engineering \& Technology, Greater Noida, India \\ ${ }^{4}$ Department of Mechanical Engineering, Noida Institute of Engineering \& Technology, Greater Noida, India
}

Received 23 May 2021; Accepted 10 September 2021

\begin{abstract}
Crowdsourcing cognitive science (CCS) provides a cutting-edge development strategy for scientific advancement and innovation to leverage the positive features of the platform. Utilizing the positive qualities of the platform and mitigating risk is the prime decisive task. The crowdsourcing paradigm shortens software development time by increasing the parallelism of design, coding and testing through flexible implementation. Although software development tasks using traditional paradigms were more complex and interdependent, they can be made easy using the crowdsourcing. CCS offers a new way for scientific advancement in this field. The objective of this study is to build more adaptable quality software. As per WHO/World Bank, 15\% people in the world have challenges due to disabilities. In the Mission 2030 for Sustainable Development, disability cannot be seen as a hurdle for the lack of digital access and for the achievement of their human rights. It is also important to reinforce the exogenous effect in order to sustain the internal development of human capital and technology for agile process convergence. Crowd-sourced design reduces development cost, time, and effort by involving intelligence, creativity, and critical thinking of people at different levels of society. In this study, internal consistency and reliability of team are also assessed with the help of Cronbach's alpha using IBM-SPSS. The given approach has been validated for its effectiveness and verified with the help of Smart India Hackathon (SIH-2019) datasets.
\end{abstract}

Keywords: Agile software development, WCAG guidelines, Team cognition, linguistic diversity, Micro-task.

\section{Introduction}

In the past decade, crowdsourcing has attracted the attention of scholars, scientists, and entrepreneurs. Compared with existing methods, the potential advantages of crowdsourcing are faster time to market, diversity of solutions, lower costs, wider participation, open innovation and better software quality [1]. It is the approach of accessing a group of people to collectively solve a specific problem in time bound manner $[2,3]$. Crowdsourcing speeds up the development cycle and enables the company to grow much less infrastructure than before, allowing the company to become more agile, ubiquitous, efficient and responsive to the on-demand market. It has proven to be very useful in machine learning, health care, linguistics, software development, and other areas of the research. Software development depicts a cognitive process which includes the thought process, creativity, and involvement of a huge number of people engaged in a global perspective [4, 5].

Although software development tasks using traditional paradigms were more complex and interdependent, they can be made easy using the crowdsourcing [6, 7]. Therefore, fragmentation of desired product into small modules that can be effectively crowd-sourced is a big challenge [8]. The software development team needs to work in a collaborative manner considering the prerogatives of different groups. The success of a team depends upon the combined effect of communication network, collaborative efforts and extent of

*E-mail address: shwetavishnoi@gmail.com ISSN: 1791-2377 @ 2021 School of Science, IHU. All rights reserved. doi:10.25103/jestr.144.03 coordination among the teammates involved in development of the software [9].

The nature of work is changing dramatically through trends such as the commercialization of expertise and the democratization of participation. Crowdsourcing has changed the existing IT business model drastically [10]. Crowdsourcing Cognitive Science offers a new way for scientific advancement in this field. Leveraging the positive qualities of the platform and mitigating risks is the deciding task [11]. Crowdsourcing platforms have become a major stakeholder in software development. Crowdsourcing can be adopted either partially or for the entire project in the software development as per the needs [12]. Any development stages or work requirements [13] maybe crowd-sourced, including design [14], coding [15], testing [16], and documentation [17].

Most of the software industries are widely adopting agile methods due to its success stories in the dynamic software development [18]. Agile approaches offer many advantages, such as increasing productivity, expanding test coverage, reducing time and costs, improving quality and increasing customer satisfaction. Due to these, agile approach is the first choice of many developers. The agile method can accept rapid changes which are occurring at all the phases of development. According to the CHAOS coverage of Standish Group 2012, agile projects are three times faster in the successful development than non-agile projects. It was also noted here that the continuous daily feedback received in retrospective meetings in the sprint process is more focused on software quality [19]. 
Diversity plays a crucial role in crowd sourcing, which is completely transforming the work culture. Spatial, racial, occupational, gender, linguistic and age are various types of differences. The linguistic diversity in crowd sourcing is the best example of this. A survey was conducted in the workshop on collaborative crowdsourcing for translation [20] and it was found that crowd workers spoke more than 5,000 languages worldwide. It is almost impossible for a company to provide the services in all languages through the in-house use of translators, but crowd-sourcing makes it possible [21].

Crowd-sourcing based software development approach has been used by many successful platforms. Top Coder, 99designs, AppStori, uTest, Mob4Hire, Applause and Test Flight have made a recognition in this regards. Many design based cognitive activities find wide applications of crowdsourcing approach. Surveys indicate that much research has been done in the field of software metrics, but the crowd sourcing approach to software development is still a challenge $[22,23]$.

The theory of team cognition is initially proposed as an effective designing and articulation mechanism for understanding interactions among teammates. Team cognition empowers the members to properly utilize the strength of each member and make predictions related to accomplishment of work. The collaborative approach results an overall increase in effectiveness of the team. Lack of wellbalanced cognition among the teammates hampers the sharing of knowledge and skills to a large extent. It can also have a negative impact on coordination of activities, resolving the disputes, and concluding the final solutions. In software development, the effective utilization of cognitive skills can be considered as an integrated asset while assigning the tasks to the most appropriate individuals, coordinates their actions and adapts their behaviors for project requirements [24, 25].

Both emotional and intelligence quotient of each individual team member are taken together into account during the team building phase. Only the intelligence quotient is insufficient to determine the performance of the team, since the intelligence quotient without emotional quotient makes the team member autocratic and the intelligence quotient with the emotional quotient democratizes the team member [26]. The team's performance is enhanced by incorporating democratic members into the team who understand the needs and feelings of themselves and others in order to maintain synergies in the team. Meta-analysis of 225 research papers with over 2,75,00 participants showed that people who felt happy were more likely to have a secure job interview, were rated more positively by supervisors, showed excellent performance and high productivity, and be better managers [27].

For measuring internal consistency of each team, we used mean, standard deviation and Cronbach's alpha $(\alpha)$ on the parameters such as communication, coordination, emotional intelligence \& cohesion, contribution \& work satisfaction, efficiency and solution approach to the problem.

The rest of this paper is organized like this. Related work and historical outlook with crowdsourcing agile environment by involving all stakeholders are discussed in Section 2 . Research methodology used in this paper has been discussed in Section 3. Section 4 discusses the results and subsequently concludes the work.

\section{Crowdsourcing Agile Environment}

For a big project, distribution of activities into independent tasks and integration of solutions into the final product is the most desired feature. Through decomposition of programs, reusability of some components of the program becomes possible. It is due the reduced size of the program code for each module. As a result, the chances of error are reduced and software development becomes a comfortable job due to easy debugging of codes. The net effect of decomposition of a project during development phase is evident when we desire modification and easy maintenance shortens the down time [28].

Micro-Tasks are the tasks that are completed in less time and together provide the solution to complex tasks or macrotasks. These are small and self-contained tasks of the large tasks, which can be distributed to arbitrarily large crowd to allow quick execution [29]. Product flexibility and comprehensibility are the two main benefits of the modular programming. In product flexibility, it should be possible to make significant changes to one module without affecting the other. In terms of comprehensibility, the system should be able to visualize a module in a clearer and wide-ranging manner [30]. The effective and efficient modularization of tasks in micro-tasks, getting sub-solutions to these microtasks and systematically integrating the sub-solutions for obtaining an optimal solution to the defined problem is an essentiality in development process [31]. The developers should know both the behavior of their module and the expected behavior of the other interacting modules according to the RASCI model as illustrated in Figure 1.

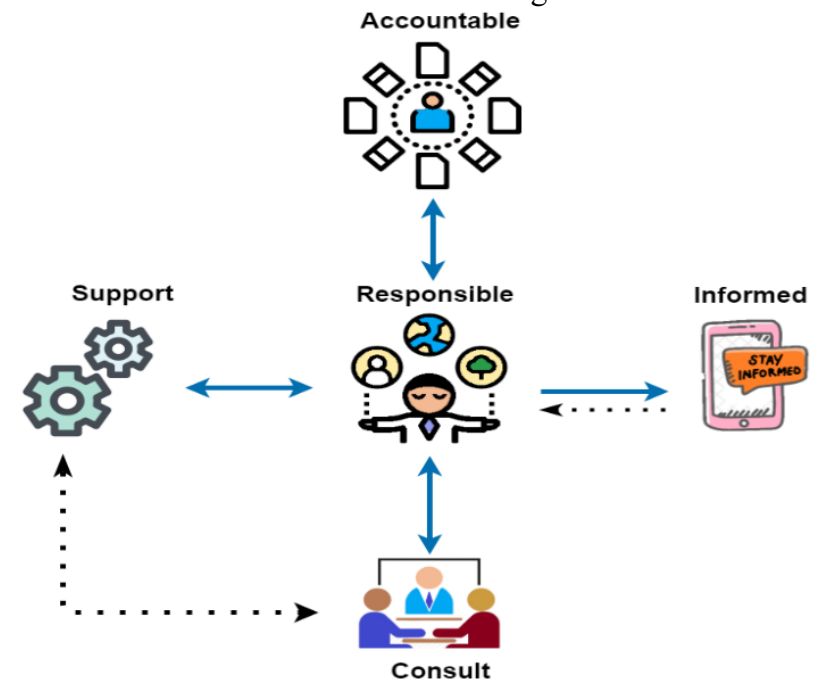

Fig. 1. RASCI model for collaborative project

RASCI metrics clearly illustrate the roles and responsibilities in large projects as those who are Responsible (who do the job, often the chief designer), Accountable (who is accountable for the thorough implementation, often a graduate supervisor or PI), Consulted (with whom there is mutual communication), Supporting (helps like a research assistant to the responsible person) and Informed (Who is up to date on progress through one-way communication, such as funders).

This paradigm is useful for reusing software code, while dealing with similar type of projects. The quick product releases will reduce the turnaround time and blocking states of system. This paradigm consists of five phases such as information acquisition with crowd sourcing, design with crowd sourcing, crowd coding, crowd testing, and review and deployment as shown in Figure 2.

\subsection{Information acquisition with crowdsourcing}

An Endogenous competence has become increasingly popular in science, technology, engineering, mathematics (STEM) 


\section{Journal of Engineering Science and Technology Review 14 (4) (2021) 18 - 25}

especially in developed countries, and has contributed significantly to the growth of the economy [32]. It is also important to reinforce the exogenous effect in order to sustain the internal development of human capital and technology for agile process convergence. Therefore, during requirements engineering (RE), the participation of stakeholders and users is essential to create a collaborative environment within a constant loopback system [33]. Crowdsourcing supports the requirements analysis phase because the crowd is a potential user that helps in creating the software requirements
specifications.At this stage, the primary goal is to capture the actual requirements of software using requirements elicitation with crowdsourcing. Software project managers use the power of crowd using brainstorming sessions, questionnaires, interviews, group discussions, ethnography and informal methods to identify, elicit or refine the requirements that are more beneficial for better understanding of software requirements specifications [34].

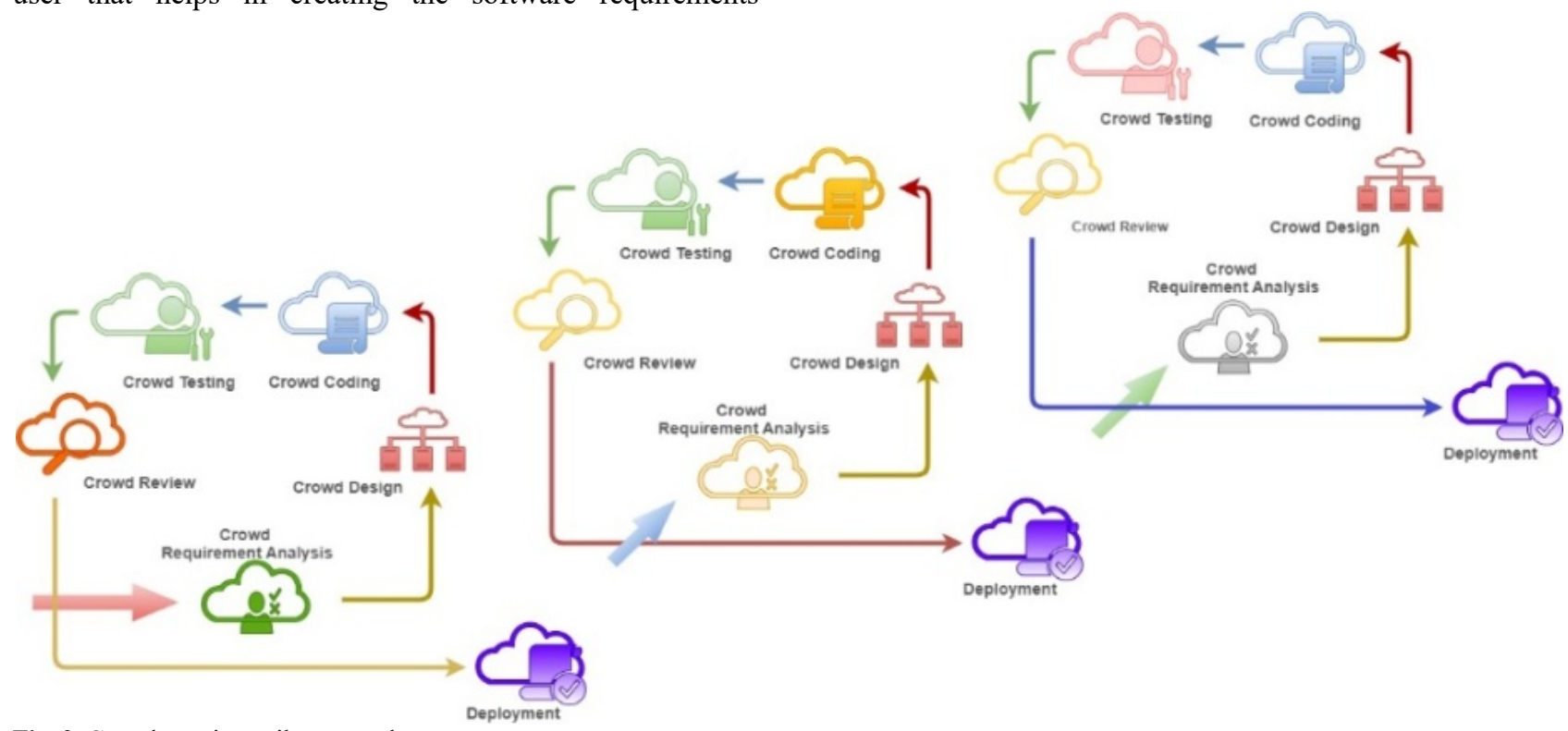

Fig. 2. Crowdsourcing agile approach.

Crowd Require is a conceptual platform that develops the requirements for projects submitted by individuals, companies or other external entities, and finds the best requirements specification for proposed tasks. The requirement elicitation is a pivotal task in software development. If a project manager has initial understanding of problem at early stage of the development process, much work of later stages can be avoided [35]. Stake Source is one of the leading social tools for identifying and prioritizing the various crowd-sourcing stakeholders, such as users, customers, developers, domain experts, etc., who are involved in software development to gain insight into the project from multiple perspectives [36]. StakeSource 2.0 is the refined version for automatically retrieving the list of prioritized stakeholders in order to gather information about projects and to save costs, time and effort for the development process [37].

iThink provides all development stakeholders with a platform for effective decision-making, ignoring unnecessary information, and anticipating the impact of action earlyfrom a new perspective. It also helps with the seamless analysis, design, testing and implementation of the project and solves the conflicting environments [38]. Refine, Requirements Bazaar, Winbook, are other web-based platform for requirements elicitation, negotiation, prioritization between End-Users and Open Source Software Developers [39].

It is based on the principles of social requirements engineering, which allows communities to express, discuss and prioritize their requirements and trace their realization in a way known from social networking. At this stage, the focus is on determining which functions need to be executed rather than how these functions should be executed [40].

\subsection{Design with crowdsourcing}

Crowd Design is a human-centric approach to develop websites, mobile apps, IOT-based applications and other products that ensure quality assurance through authentic insights from real crowd content to create optimal solutions. Crowd-sourced design reduces development cost, time, and effort by involving intelligence, creativity, and critical thinking of people at different levels of society. It can be divided into five areas such as graphical user interface design, architecture design, module design, database design, and content accessibility design [41]. The WHO/World Bank report reveals that almost one billion people in the world experience some form of disability and the agenda for Sustainable Development by 2030 envisions that disability should not be a barrier in the software development and ensuring human rights [42].

ISO / IEC 40500: 2012- The guidelines for web content accessibility recommend making web content accessible to all. The guidelines reflect the vision to make the software accessible to the people with disabilities, such as low vision or complete blindness, impaired hearing or deafness, learning impairments, low cognitive skills, limited psychomotor skills and speech related problem. In June 2018, WCAG 2.1 was released with seventeen new policies focused on improving accessibility for users with cognitive disabilities and users browsing websites on mobile devices such as tablets and smartphones [43].

Other design platforms such as Applause, DesignCrowd and crowdSPING can also be used for higher order cognitive skills [44]. An effective software design paradigm attained by using the data and features suggested by the end users proves crowdsourcing a prominent software development tool [45]. However, in the context of web engineering the designs are 
specific website components. The results show that the outcome of the experiment conducted depend upon various factors such as; motivation level of participants, the strategy for quality assurance, the desired security features and the intellectual property rights involved.

\subsection{Coding with Crowdsourcing}

The key challenge is to find a suitable general-purpose coding platform where the requesters describe and publish problems, and offer or compete with different programmers to provide solutions to the published task. Bountify, Topcoder, and Applause are the convenient platforms on which a Q \& A session has been conducted to enhance crowdsourcing coding tasks [46]. The key components of software coding in crowdsourcing environment include: crowd programming in an open-source system, code optimization, and integrated development environment (IDE) for editing, compiling, debugging, and executing the source code [47].

An open software system (OSS) such as Google code should be promoted, by which all coders are communicated and worked together. On this, users can upload, edit and publish their problems. If conflicts arise, they can be solved democratically by voting. It's free, but the rights to learn, modify and distribute may be limited by the license [48].

\subsection{Crowd-Testing}

Crowd Testing uses all kinds of software tests, such as functional tests, structure tests, utility tests, stress tests, accessibility tests, and security tests using the UTest platforms, using the skills of experienced testers [49]. It is very effective in designing various test cases of the software. This platform provides registered testers with learning manuals as well as a list of all testers with their respective capability rates. Testers are rewarded as theirefforts to figure out the number of bugs. This platform also provides a forum for discussions, chats, conversations, e-mails, and invitations to coordinate all test processes and support communication among all testers, even though they do not cooperate much by being independently involved in the test work [50]. 99tests, Bugcrowd, TestFlight and Testbirds are the leading crowdsourced software testing companies that have a diverse pool of testers across the world for the execution of test tasks. This platform provides help with finding errors as well as a tester to check the errors found in the test cycle [51].

\section{Discussion}

Post-mortem review is essentially required to implement the project successfully. The post-mortem review examines the root causes of the success and failure of each project component involving all stakeholders. Whatever things are revealed during the project review, they have been documented to take corrective action down the line. During review processes, lessons learned are documented and used in the sprint releases of the products. Plan, design, review, and deploy steps are used in each sprint to develop product iteratively and incrementally simultaneously. Here, we always welcome user's changes and incorporate that in next sprint to add additional value to the product. In this retrospective review, testers feel proud on constructive criticism. With the help of review document pearl of wisdom is shared among the testers who face the same challenges. Scrum platform is used for review and deployment of the product which can sustain in global environment for long time and can gain strategic advantages over other competitive products [52, 53].

Figure 3 shows that the term "crowdsourcing" has been adopted and embraced worldwide with gusto. IT-based crowdsourcing is defined as the outsourcing of technical support for tasks through open calls to the masses over the internet. Crowdsourcing is an IT artifact; it has gone way beyond that the traditional boundaries of the organization on a larger scale. Crowd-testing is in its early stages and is still seeking attention. In general, the development processes of software projects are organized in a series of tasks. The main goal of these tasks is the design, development, testing and deployment of project modules [54].

SIH is a national competition orgnised by Government of India to promote the culture of developing solutions to real time problems of different ministries and industries by the youth through disruptive digital technology innovations. In the competition a three days long non-stop product development event is organised, where the technology experts act as mentors and end users are part of evaluation team. The event offers an opportunity to college students to propose solutions based on disruptive technologies and associate with companies of repute.

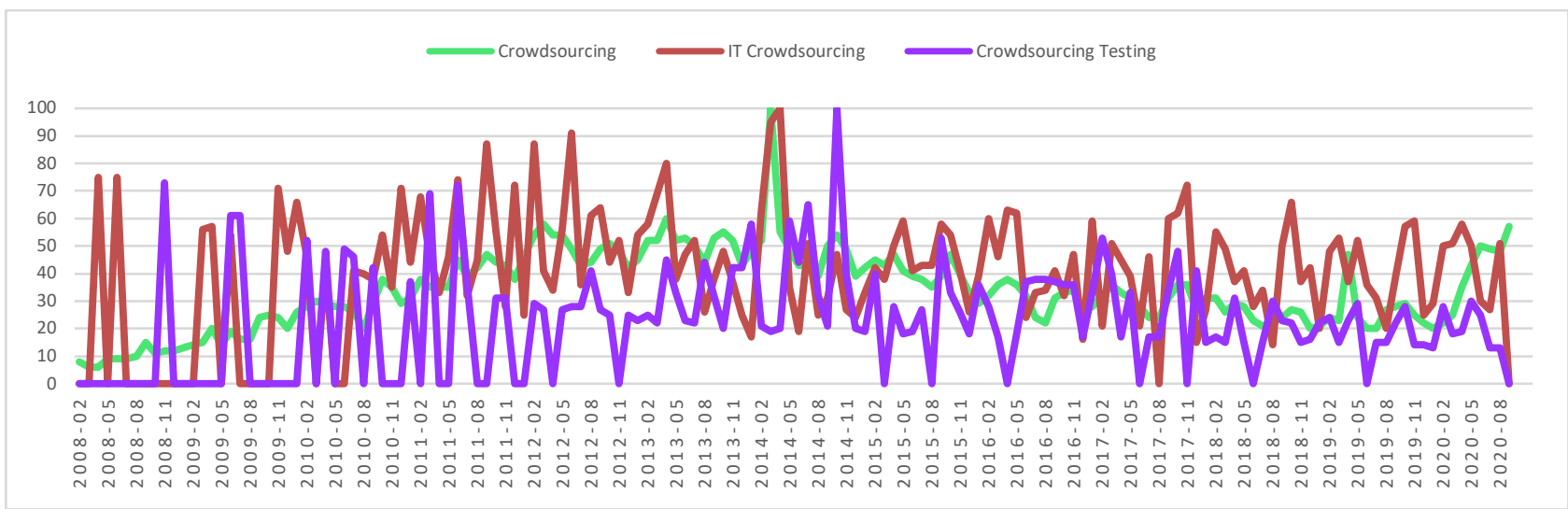

Fig. 3. Google trend of crowdsourcing, IT-Crowdsourcing \& Crowd-testing from 2008 -2020.

The report of Press Information Bureau [PRID=156598], Govt. of India states that SIH-2019 finale was the world largest Hackathon event organised at the national level. Before that, two editions of $\mathrm{SIH}$ had been conducted successfully in Year 2017 and 2018. The approximately
34,000 teams participated in this event from all over India. More than 500 problem statements from different software industries, state ministries, and ministries of government of India were received for solving their problems. The Grand Finale of the Software edition (SIH-2019) took place on 2nd 
- 3rd March, 2019, where 1391 teams were selected for completing their projects continuously in 36 hours across 48 different nodal centers in India. Based on the continuous participation of the last two years (2017 and 2018) of our various teams, SIH has provided us with a good lesson in the development of paradigm policies and strategies, defining best practices and their implementation. We achieved encouraging results in SIH-2019 by adopting the proposed approach. Our study is based on 54 participating teams who wanted to submit their ideas to find the solution to the problems posed by SIH. These teams included 54 team leaders, 378 team members, and 70 mentors. The 24 teams were selected by screening based on questionnaire, as mentioned in appendix A (Team cognition).

On the basis of the survey received from different team members in the form of questionnaire, we interviewed and monitored the performance of all team members who evinced their willingness for this event. After rigorous review of teams' performance by academicians and industry experts, twenty-four teams were selected in SIH-2019.

Cronbach's alpha offers a way of measuring the strength of consistency and evaluate the reliability of the test. The formula for the Cronbach's alpha [55] is as

$$
\alpha=\frac{k \bar{r}}{(1+(k-1) \bar{r})}
$$

Where, k refers the number of indicators/items and $\bar{r}$ shows the mean inter-indicator/item correlation.

In order to determine how each question in the test affects reliability, for each $i \leq k$, Cronbach's alpha can be calculated after clearing the $\mathrm{i}^{\text {th }}$ variable. Therefore, to examine with $\mathrm{k}$ questions, the score for each question is $\mathrm{x}_{\mathrm{j}}$, and Cronbach's alpha will be calculated for $x_{i}^{*}$ for all $i$ where $x_{i}^{*}=\sum_{j \neq i} x_{j}^{*}$ The general discourse is that the Cronbach's alpha value of .70 and above is considered as good [56]. The value of Cronbach's alpha of all qualified team based on the questionnaire of 168 members is 0.769 as depicted in Table1. The team with Cronbach's alpha value above the average value of 0.769 is considered as a very good team. On the other hand, the team below 0.769 can be considered as relatively less synergic among team members.

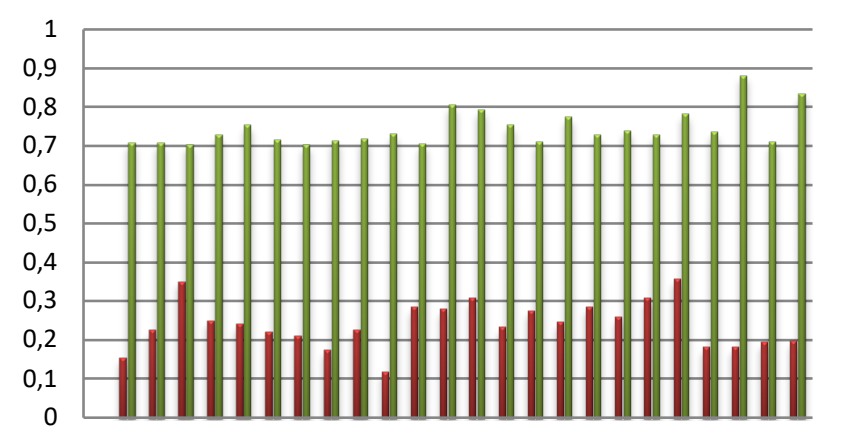

A B CDEFGH I J K L M OPQR S T U VWX Team Name

$\square \sigma \quad \square \alpha$

Fig. 4. Performance metric of selected teams in SIH-2019.

$\underline{\text { Table 1. Reliability Statistics of all team's vs team V }}$

\begin{tabular}{c|c|c|c}
\hline Table 1. Reliability Statistics of all team's vs team V & $\boldsymbol{\alpha}$ & A (Standardized Items) & Parameter \\
\hline Team & .880 & .886 & 6 \\
X (7 members) & .769 & .772 & 6 \\
\hline
\end{tabular}

\section{Results}

The performance metric, Cronbach's alpha was computed from mean and standard deviation $(\sigma)$ of the above parameters and is shown in figure 4 . The team with higher Cronbach's alpha was assumed to exhibit more internal reliability and consistency among the team members and given priority for selection [57].

In this study, Cronbach's alpha is used to assess the internal consistency and reliability of the teams. IBM-SPSS is used to analyze the data. Cronbach's alpha has evolved as prominent method to measure the internal consistency and the reliability of the team work. Two teams (V and X) out of 24 teams eventually got selected for the Grand Finale of Hackathon, where 1389 teams of students from other institutions were selected for final round from all over the country and 319 team got declared winner on the national level. The team $\mathrm{V}$ was the winner and team $\mathrm{X}$ was runner up. The problem statement of winning team was high performance network intrusion detection engine provided by Quick Heal. The winner team also followed WCAG guidelines that were more helpful for their projects. Results clearly show that the team V having Cronbach's alpha value 0.880 won the final round because of strong synergy among its members.

The inter-parameters correlation matrix of the winner team is shown in Table 2. It indicates that each parameter with all the other parameters for measuring the team's performance is highly correlated except correlation of efficiency with coordination. The results comprehensively support the proposed approach, highlighting the quality of team work performance.

\section{Conclusion}

In this paper, the use of crowdsourcing cognitive science for agile software development offers valuable benefits leading to more relevant and creative requirements, improving the ability to understand the basics of requirements, and having complete solutions. The main platforms using crowdsourcing for design, coding, and testing were analyzed and the basic activities were listed and defined in detail. The results clearly show that it plays a decisive role in the success of the project. Web content accessibility guidelines (WCAG) provide a better digital accessibility solution for people with cognitive impairment.

Crowdsourcing is not a panacea for all the problems and can lead to terrible results if it is not managed carefully. It should be done with expertise of those who ensure what one gets and is actually needed to be done at the end of the project. It has been observed and analyzed that the methodological rigor with emotional intelligence, whenever applied in the right perspective produces the better outcome ultimately 
leading to the happiness of individual and whole team. An implication of this study is that consistency and reliability are two main factors for improving the team's performance. The cognitive team spirit plays a vital role in enabling team members to rely upon their strengths in selection of tasks according to compatibility and coordination with their teammates.

Table 2. Inter-Item correlation matrix of V team

\begin{tabular}{|c|c|c|c|c|c|c|}
\hline & 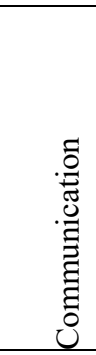 & 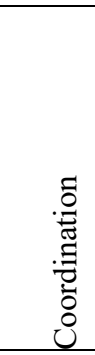 & 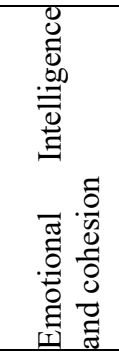 & 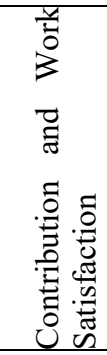 & 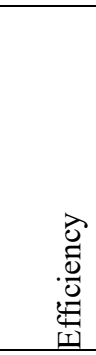 & 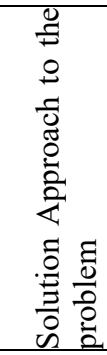 \\
\hline Communication & 1.000 & .411 & .645 & .884 & .645 & .867 \\
\hline Coordination & .411 & 1.000 & .636 & .645 & .141 & .400 \\
\hline Emotional Intelligence and cohesion & .645 & .636 & 1.000 & .730 & .300 & .354 \\
\hline Contribution and Work Satisfaction & .884 & .645 & .730 & 1.000 & .730 & .710 \\
\hline Efficiency & .645 & .141 & .300 & .730 & 1.000 & .354 \\
\hline Solution Approach to the problem & .867 & .400 & .354 & .710 & .354 & 1.000 \\
\hline
\end{tabular}

For future, we recommend to construct prediction model for assessing the internal consistency among team members and reliability of team work on the basis of some more innovative parameters. This futuristic approach can also be used to develop projects on complex problems of modern science, such as IOT-based analysis, big data analysis, cloud computing, artificial intelligence, and virtual or augmented reality, etc.

\section{Acknowledgements}

Our sincere gratitude to all those team who have participated in SIH-2019. Our sincere and heartiest thank to MHRD, Government of India and AICTE for organizing this mega event. We extend our sincere thanks to all the partners who have given their problem statements to different teams.

This is an Open Access article distributed under the terms of the Creative Commons Attribution License.

\section{References}

1. Singhal, A., Kumar, P., Saini, R., Roy, P.P., Dogra, D.P. and Kim, B.G., 2018. Summarization of videos by analyzing affective state of the user through crowdsource. Cognitive Systems Research, 52, pp.917-930.

2. Ford, R. C., Richard, B., \& Ciuchta, M. P., (2015). Crowdsourcing: A new way of employing non-employees? Business Horizons, 58(4), 377-388.

3. Saab, F., Elhajj, I.H., Kayssi, A. and Chehab, A., 2019. Modelling Cognitive Bias in Crowdsourcing Systems. Cognitive Systems Research, 58, pp.1-18

4. Hansson, K., Ludwig, T. and Aitamurto, T., 2019. Capitalizing Relationships: Modes of Participation in Crowdsourcing. Computer Supported Cooperative Work (CSCW), 28(5), pp.977-1000.

5. Hosseini, M., Shahri, A., Phalp, K., Taylor, J. and Ali, R., 2015. Crowdsourcing: A taxonomy and systematic mapping study. Computer Science Review, 17, pp.43-69.

6. Guo, B., Liu, Y., Wang, L., Li, V. O., Lam, J. C., \& Yu, Z. (2018). Task allocation in spatial crowdsourcing: Current state and future directions. IEEE Internet of Things Journal, 5(3), 1749-1764.

7. Hasteer, N., Nazir, N., Bansal, A. and Murthy, B.K., 2016. Crowdsourcing software development: Many benefits many concerns. Procedia Computer Science, 78, pp.48-54.

8. LaToza, T. D., Towne, W. B., Hoek, A. van der, \&Herbsleb, J. D. (2013). Crowd development, in Proc. 6th CHASE Workshop. IEEE,

9. Yagüe, A., Garbajosa, J., Díaz, J. and González, E., 2016. An exploratory study in communication in Agile Global Software Development. Computer Standards \& Interfaces, 48, pp.184-197.

10. Sievi-Korte, O., Beecham, S., \& Richardson, I. (2019) Challenges and recommended practices for software architecting in global software development. Information and Software Technology, 106, 234-253.
11. Stewart, N., Chandler, J., \&Paolacci, G. (2017) Crowdsourcing Samples in Cognitive Science Box:MTurk Terms, Trends in Cognitive Sciences, 111, 1-19.

12. Retelny, D., Bernstein, M. S., \& Valentine, M. A. (2017). No workflow can ever be enough: How crowdsourcing workflows constrain complex work. Proceedings of the ACM on HumanComputer Interaction, $1(\mathrm{CSCW}), 89$.

13. Li, C., Huang, L., Ge, J., Luo, B. and Ng, V., 2018. Automatically classifying user requests in crowdsourcing requirements engineering. Journal of Systems and Software, 138, pp.108-123.

14. Wu, H., Corney, J. and Grant, M., 2015. An evaluation methodology for crowdsourced design. Advanced Engineering Informatics, 29(4), pp.775-786.

15. Jacobson, M.R., Whyte, C.E. and Azzam, T., 2018. Using crowdsourcing to code open-ended responses: A mixed methods approach. American Journal of Evaluation, 39(3), pp.413-429.

16. Tung, Y.H. and Tseng, S.S., 2013. A novel approach to collaborative testing in a crowdsourcing environment. Journal of Systems and Software, 86(8), pp.2143-2153.

17. Bazilian, M., Rice, A., Rotich, J., Howells, M., DeCarolis, J., Macmillan, S., Brooks, C., Bauer, F. and Liebreich, M., 2012. Open source software and crowdsourcing for energy analysis. Energy Policy, 49, pp.149-153.

18. Curcio, K., Santana, R., Reinehr, S. and Malucelli, A., 2019. Usability in agile software development: A tertiary study. Computer Standards \& Interfaces, 64, pp.61-77.

19. Mishra, D., \&Abdalhamid, S. (2018). Software Quality Issues in SCRUM: A Systematic Mapping, Journal of Universal Computer Science, 24(12), 1690-1716.

20. Munro, R., (2010). Crowd sourced translation for emergency response in Haiti: the global collaboration of local knowledge. AMTA Workshop on Collaborative Crowdsourcing for Translation. 


\section{Raj Kumar Goel, Chandra Shekhar Yadav, Shweta Vishnoi, Laxman Singh and Praveen Pachauri/ \\ Journal of Engineering Science and Technology Review 14 (4) (2021) 18 - 25}

21. Naik, N., (2017). Software CROWD-sourcing. In Proceedings International Conference on Research Challenges in Information Science, 463-464.

22. Mao, K., Capra, L., Harman, M., \& Jia, Y. (2017). A survey of the use of crowdsourcing in software engineering. Journal of Systems and Software, 126, 57-84.

23. Zogaj,S., Bretschneider, U., \& Leimeister, J., M, (2014) Managing crowdsourced software testing: A case study-based insight on the challenges of a crowdsourcing intermediary, Journal of Business Economics, 84, 375-405.

24. He, J., Butler, B.S. and King, W.R., 2007. Team cognition: Development and evolution in software project teams. Journal of Management Information Systems, 24(2), pp.261-292.

25. Beck, S.J. and Keyton, J., 2013: Team Cognition, Communication, and Message Interdependence. In Theories of Team Cognition (pp. 497-520). Routledge.

26. Gondal, U.H. and Husain, T., 2013. A comparative study of intelligence quotient and emotional intelligence: effect on employees' performance. Asian journal of Business management, 5(1), pp.153-162.

27. Lyubomirsky, S., King, L., \& Diener, E. (2005). The benefits of frequent positive affect: Does happiness lead to success? Psychological Bulletin, 131(6), 803-855.

28. Gorelik, A.M., 2006. Modern technologies aimed at the development of large programs for solving computational problems on computers with various architectures. Programming and Computer Software, 32(6), pp.338-347.

29. Hansson,K., \& Ludwig, T., (2018). Crowd Dynamics: Conflicts, Contradictions, and Community in Crowdsourcing. Computer Supported Cooperative Work (CSCW), 2013-2016.

30. Landwehr, C., Ludewig, J., Meersman, R., Parnas, D. L., Shoval, P., Wand, Y., \&Weyuker, E. (2017). Software Systems Engineering programmes a capability approach, Journal of Systems and Software, 2017, 125, 354- 364.

31. LaToza, T.D., Towne, W.B., \& Hoek, A.V.D. (2014). Harnessing the crowd: Decontextualizing software work, in: Proc. 1st International Workshop on Context in Software Development Workshop, 2-3

32. Sieroń, A., 2019. Endogenous versus exogenous money: Does the debate really matter? Research in Economics.73 (2019) 329-338.

33. Schön, E.M., Thomaschewski, J. and Escalona, M.J., 2017. Agile Requirements Engineering: A systematic literature review. Computer Standards \& Interfaces, 49, pp.79-91.

34. Stol, K. J., Latoza, T. D., \& Bird, C. (2017) Crowdsourcing for Software Engineering. IEEE Software, 34(2), 30-36.

35. Adepetu, A., Khaja, A.A., Al Abd, Y., Al Zaabi, A. and Svetinovic, D., 2012, March. Crowdrequire: A requirements engineering crowdsourcing platform. In 2012 AAAI Spring Symposium Series.

36. Lim, S., Quercia, D., \& Finkelstein, A. (2010). StakeSource: Harnessing the power of crowdsourcing and social networks in stakeholder analysis. In: Proceedings of the 32nd ACM/IEEE International Conference on Software Engineering.

37. Hujainah, F., Bakar, R.B.A., Al-Haimi, B. and Abdulgabber, M.A., 2018. Stakeholder quantification and prioritisation research: A systematic literature review. Information and Software Technology, 102, pp.85-99.

38. Seaborn, K. and Fels, D.I., 2015. Gamification in theory and action: A survey. International Journal of human-computer studies, 74, pp.14-31.

39. Alyahya, S., Alohali, W., \& Al-Balhareth, S. (2018). Enhancements for crowdsourced requirements engineering. Journal of Theoretical and Applied Information Technology, 96(12), 3815-3828.
40. Gharib,M., \&Giorgini, P. (2019) Information quality requirements engineering with STS-IQ, Information and Software Technology, $107,83-100$.

41. Sharafi, Z., Soh, Z., \&Guéhéneuc, Y. G., (2015) A systematic literature review on the usage of eye-tracking in software engineering, Information and Software Technology, 2015, 67, 79107.

42. Lewis C., Seeman L. (2019) Policy and Standards on Web Accessibility for Cognitive and Learning Disabilities. In: Yesilada Y., Harper S. (eds) Web Accessibility. HumanComputer Interaction Series. Springer, London

43. Crespo, R.G., Espada, J.P. and Burgos, D., 2016. Social4all: Definition of specific adaptations in Web applications to improve accessibility. Computer Standards \& Interfaces, 48, pp.1-9.

44. Allen,B. J., Chandrasekaran, D., \&Basuroy, S., (2013). Design Crowdsourcing: The Impact on New Product Performance of Sourcing Design Solutions from the Crowd, Journal of Marketing, 82(March), 106-123.

45. Nebeling,M., Leone, S., \& Norrie, M., (2012). Crowdsourced web engineering and design, in: Proc. 12th International Conference on Web Engineering, 1-15.

46. Bari, E., Johnston, M., Wu, W. and Tsai, W.T., 2016, March. Software crowdsourcing practices and research directions. In 2016 IEEE Symposium on Service-Oriented System Engineering (SOSE) (pp. 372-379). IEEE.

47. Ge, X., Shepherd, D. C., Damevski, K., \& Murphy-Hill, E. (2017) Design and evaluation of a multi-recommendation system for local code search, Journal of Visual Languages and Computing, 39, 1-9

48. Bonaccorsi, A., \& Rossi, C. (2003). Why open source software can succeed. Research Policy, 32(7), 1243-1258.

49. Alyahya, S. and Alrugebh, D., 2017. Process improvements for crowdsourced software testing. International Journal of Advanced Computer Science and Applications, Vol. 8, No. 6 pp 32-40.

50. Leicht, N., Blohm, I., \&Leimeister, J. M. (2017).Leveraging the Power of the Crowd for Software Testing, IEEE Software, 34(2), 62 69

51. Guo, S., Chen, R., Li, H., Gao, J., \& Liu, Y. (2018). Crowdsourced Web Application Testing Under Real-Time Constraints. International Journal of Software Engineering and Knowledge Engineering, 28(06), 751-779.

52. Pikkarainen, M., Salo, O., Kuusela, R., Abrahamsson, P. (2012) Strengths and barriers behind the successful agile deployment insights from the three software intensive companies in Finland, Empirical Software Engineering, 17 (6), 675-702

53. Tasharofi,S., \&Ramsin, R., (2007) Process Patterns for Agile Methodologies. In: Ralyté, J., Brinkkemper, S., Henderson-Sellers, B. (eds.) Situational Method Engineering: Fundamentals and Experiences, 222-237. Springer, Heidelberg.

54. Modaresnezhad, M., Iyer, L., Palvia, P. and Taras, V., 2020. Information Technology (IT) enabled crowdsourcing: A conceptual framework. Information Processing \& Management, 57(2), p.102135.

55. Nunnally, J., Bernstein, I. H., (1994) Psychometric theory, 3rd Edition, New York: McGraw-Hill.

56. Taber, K. S., (2018) The Use of Cronbach's Alpha When Developing and Reporting Research Instruments in Science Education. Research in Science Education, 48(6), 1273-1296.

57. Han, X., Gong, X. and Zhang, P., 2018. Online labor service crowdsourcing analysis based on linear discriminant regression. Cognitive Systems Research, 52, pp.168-173 


\begin{tabular}{|c|c|c|}
\hline \multicolumn{3}{|c|}{ Communication } \\
\hline S.NO & Question & Frequency \\
\hline 1. & Is there frequent meeting in the team? & (once/twice /thrice in a week/daily) \\
\hline 2. & Which medium has been used for organizing the meeting & $\begin{array}{l}\text { (phone/chat/videoconferencing /board } \\
\text { room meeting) }\end{array}$ \\
\hline 3. & $\begin{array}{l}\text { Idea, plan and information which are pertinent to teamwork are } \\
\text { discussed openly } \\
\text { among all team members }\end{array}$ & (very few /few /Many/All team member). \\
\hline 4. & $\begin{array}{l}\text { Satisfaction of team members with the timelines in receiving } \\
\text { information from other members. }\end{array}$ & $\begin{array}{l}\text { (slightly satisfied/ satisfied/ highly } \\
\text { satisfied) }\end{array}$ \\
\hline 5. & Usefulness of the information received from other members. & (low/Average/High/ Extremely High) \\
\hline \multicolumn{3}{|c|}{ Coordination } \\
\hline 6. & $\begin{array}{l}\text { Subtasks goals (Responsibility assignment) are accepted by all team } \\
\text { members. }\end{array}$ & (very few /few /Many/All team member) \\
\hline 7. & $\begin{array}{l}\text { In team, there are conflicting interests (Cognitive dissonance) } \\
\text { regarding subtasks / sub goals. }\end{array}$ & (Slightly/moderately/strongly/firmly) \\
\hline 8. & There are clear and fully understood goals for subtasks in the team. & (Slightly/moderately/strongly/firmly) \\
\hline 9. & The work on subtasks within the team is closely coordinated. & (Slightly/moderately/strongly/firmly) \\
\hline \multicolumn{3}{|c|}{ Emotional intelligence and Cohesion } \\
\hline 10. & Will you be in touch with your current & (Very few /few /Many/All team member). \\
\hline 11. & Describe a time when you resolved a conflict during work. & (Very few /few /Many/All team member). \\
\hline 12. & How do you establish a relationship with your colleagues? & (Slightly/moderately/strongly/firmly) \\
\hline 13. & Can & (Slightly/moderately/strongly/firmly) \\
\hline 14. & Are the team members emotional & (Very few /few /Many/All team member). \\
\hline \multicolumn{3}{|c|}{ Contribution \& Work Satisfaction } \\
\hline 15. & $\begin{array}{l}\text { Team distributes the work as per strengths and weaknesses of each } \\
\text { team member. }\end{array}$ & $\begin{array}{l}\text { (Slightly / moderately / considerably / } \\
\text { extremely) }\end{array}$ \\
\hline 16. & & $\begin{array}{l}\text { (Slightly / moderately / considerably / } \\
\text { extremely) }\end{array}$ \\
\hline 17. & The team members gain from the collaborative teamwork & $\begin{array}{l}\text { (Slightly / moderately / considerably / } \\
\text { extremely) }\end{array}$ \\
\hline 18. & $\begin{array}{l}\text { The team members will like to do this type of collaborative work } \\
\text { again }\end{array}$ & $\begin{array}{l}\text { (Slightly / moderately / considerably / } \\
\text { extremely) }\end{array}$ \\
\hline 19. & We are able to acquire important know-how through this teamwork. & $\begin{array}{l}\text { (Slightly / moderately / considerably / } \\
\text { extremely) }\end{array}$ \\
\hline \multicolumn{3}{|c|}{ Efficiency } \\
\hline 20. & The company is satisfied with how the teamw & $\begin{array}{l}\text { (Slightly / moderately / considerably / } \\
\text { extremely) }\end{array}$ \\
\hline 21. & Overall, the team works in a cost-efficient way & $\begin{array}{l}\text { (Slightly / moderately / considerably / } \\
\text { extremely) }\end{array}$ \\
\hline 22. & Overall, the team works in a time-efficient way & $\begin{array}{l}\text { (Slightly / moderately / considerably / } \\
\text { extremely) }\end{array}$ \\
\hline 23. & The team is within schedule & $\begin{array}{l}\text { (Slightly / moderately / considerably / } \\
\text { extremely) }\end{array}$ \\
\hline 24. & The team is within budget & $\begin{array}{l}\text { (Slightly / moderately / considerably / } \\
\text { extremely) }\end{array}$ \\
\hline \multicolumn{3}{|c|}{ Solution Approach to the Problem } \\
\hline 25. & $\begin{array}{l}\text { Does the solution address the requirements for the given } \\
\text { Ministry's/technical/ITproblem? }\end{array}$ & $\begin{array}{l}\text { (Slightly / moderately / considerably / } \\
\text { extremely) }\end{array}$ \\
\hline 26. & What type of technical input is needed to solve the problem? & $\begin{array}{l}\text { (Slightly / moderately / considerably / } \\
\text { extremely) }\end{array}$ \\
\hline 27. & $\begin{array}{l}\text { Has the solution been innovatively designed using latest } \\
\text { technologies? }\end{array}$ & $\begin{array}{l}\text { (Slightly / moderately / considerably / } \\
\text { extremely) }\end{array}$ \\
\hline 28. & Is the solution completely implemented? & $\begin{array}{l}\text { (Slightly / moderately / considerably / } \\
\text { extremely) }\end{array}$ \\
\hline 29. & How does the user experience the usefulness of the product? & $\begin{array}{l}\text { (Slightly / moderately / considerably / } \\
\text { extremely) }\end{array}$ \\
\hline
\end{tabular}

